\title{
Autologous extracellular Hsp70 exerts a dual role in rheumatoid arthritis
}

\author{
Stefan Tukaj ${ }^{1}\left(\mathbb{D} \cdot\right.$ Jagoda Mantej $^{1} \cdot$ Michał Sobala $^{2} \cdot$ Katarzyna Potrykus $^{2} \cdot$ Krzysztof Sitko $^{1}$
}

Received: 24 February 2020 / Revised: 17 April 2020 / Accepted: 22 April 2020 / Published online: 1 May 2020

(C) The Author(s) 2020

\begin{abstract}
Extracellular heat shock proteins (Hsp) influence the adaptive immune response and may ameliorate pathogenesis of autoimmune diseases. While some preclinical observations suggest that highly conserved bacterial and/or murine Hsp70 peptides have potential utility in treatment of rheumatoid arthritis (RA) via induction of T regulatory cells (Treg), the role of extracellular inducible human Hsp70 in adaptive immune processes requires further investigation. The present study evaluated Hsp70 influence on inflammatory cytokine-mediated modulation of T cell immunophenotype in ways that influence RA onset and severity. Initial experiments in the present investigation revealed that serum levels of Hsp70 are approximately 2-fold higher in RA patients versus healthy control subjects. To explore the effect of extracellular Hsp70 on key processes underlying the adaptive immune system, the effects of a highly pure, substrate-, and endotoxin-free human Hsp70 on polarization of the T helper cell subpopulations, including CD $4^{+} \mathrm{IL}-17^{+}$(Th17), $\mathrm{CD}^{+} \mathrm{FoxP}^{+}$(Treg), $\mathrm{CD} 4^{+} \mathrm{IFN}-\gamma^{+}$(Th1), and CD4 ${ }^{+} \mathrm{IL}-4^{+}$(Th2), were studied in naïve human peripheral blood mononuclear cell (PBMC) cultures stimulated with anti-CD3/28 mAb. Major findings included an observation that while Hsp70 treatment increased Th17 frequencies and Th17/Treg ratio, the frequency of Th1 cells and the Th1/ Th2 ratio were significantly decreased in the Hsp70-treated PBMC cultures. Moreover, data shown here provides preliminary suggestion that major contributing Hsp70-mediated immunomodulation includes interleukin 6 (IL-6) influence on Th17/Treg and Th1/Th2, since expression of this inflammatory cytokine is enhanced by in vitro Hsp70 treatment. These results are nevertheless preliminary and require further investigation to validate the above model.
\end{abstract}

Keywords Heat shock proteins, HSP · T helper cell (Th) populations $\cdot$ Rheumatoid arthritis, RA $\cdot$ Hsp70

\section{Introduction}

Rheumatoid arthritis (RA) is one of the most common chronic autoimmune diseases characterized by synovial inflammation and bone erosion. This disease affects up to $1 \%$ of the worldwide population. The pathogenesis of RA is driven by an inflammatory network in which both the innate and adaptive immune systems, including the immune complex-mediated complement activation, and the pro-inflammatory cytokine networks support the disease progression (Firestein and McInnes 2017). Cells of the adaptive immune systems play

Stefan Tukaj

stefan.tukaj@biol.ug.edu.pl

1 Department of Molecular Biology, Faculty of Biology, University of Gdańsk, Wita Stwosza 59, 80-308 Gdańsk, Poland

2 Department of Bacterial Molecular Genetics, Faculty of Biology, University of Gdańsk, Gdańsk, Poland a critical role in autoimmunity. Dysregulation of this arm of the immune response seems to be responsible for the development of RA (Angelotti et al. 2017) and is influenced by both the genetic and environmental factors. In the past, RA was considered as an autoimmune disease driven by proinflammatory $\mathrm{CD} 4^{+} \mathrm{IFN}-\gamma^{+}$(Th1) T helper cells which predominate over the $\mathrm{CD} 4^{+} \mathrm{IL}-4^{+}$(Th2) subset that exerts regulatory functions (Schulze-Koops and Kalden 2001). Nowadays, both the Th1 and the pro-inflammatory CD4 ${ }^{+} \mathrm{IL}-17^{+}$(Th17) T helper cells are thought to play an important role in the initiation of RA (McInnes and Schett 2011). The balance between Th17 and T regulatory (Treg) cells is crucial for the immune homeostasis protecting against the autoimmune response in RA (Schinnerling et al. 2017).

Cell-protecting heat shock proteins (Hsp) possess a dual role in the immune-mediated disorders, i.e., they are involved in the induction and propagation of autoimmune diseases, but also play a role in suppressing them. Such an equivocal role of those chaperones depends on the Hsp class, the site of inflammation, 
and the type of disease (Radons 2016; Pockley and Henderson 2018). Increased levels of Hsp70 and autoantibodies to Hsp70 in sera of RA or juvenile idiopathic arthritis (JIA) patients are found to be associated with the disease progression and activity (Zlacka et al. 2006; Najafizadeh et al. 2015), and numerous in vitro studies indicated pro-inflammatory properties for Hsp70 in their interactions with the innate immune cells. However, some of these later inflammatory effects may have resulted from the presence of endotoxins in the recombinant protein preparations (Borges et al. 2012; Pockley and Henderson 2018). In contrast to the reported Hsp70 pro-inflammatory properties, a body of literature indicates that these chaperones can have profound antiinflammatory effects and the presence of correlations between the disease activity and Hsp70 expression may be an accompanying phenomenon (van Eden 2018). Pre-clinical observations have proven that artificial immunization with highly conserved bacterial and/or murine Hsp70 peptides could be regarded as a potential treatment target for rheumatoid arthritis (RA) via induction of antigen-specific Treg cells (Wendling et al. 2000; van Eden et al. 2005; Wieten et al. 2009; van Herwijnen et al. 2012; van Eden et al. 2013; Tukaj and Kaminski 2019). Nevertheless, the role of extracellular inducible human Hsp70 in adaptive immune processes requires further investigation.

Here, the effects of highly pure, substrate-, and endotoxinfree human extracellular Hsp70 on polarization of the major human $\mathrm{T}$ helper cell subsets, such as Th1, Th2, Th17, and Treg, are explored in vitro in the context of RA development.

\section{Materials and methods}

\section{Patients and controls}

Twenty-seven patients with RA, fulfilling the ACR classification criteria from 1987 for this disease, and 37 healthy controls were included in this study. The disease activity was assessed according to the Disease Activity Score, including 28 joint counts (DAS 28-ESR = DAS 28), and joint damage was evaluated based on the Steinbrocker radiographic criteria. The use of human biological material was approved by the Ethics Committee of the Medical University of Gdańsk, Poland, and written informed consent was obtained according to the Declaration of Helsinki.

\section{Cloning, expression, and purification of human Hsp70}

Synthetic DNA fragment encoding Hsp70 (HSPA1A) from Homo sapiens (NP 005336.3) has been obtained from Thermo Scientific (GeneArt service). Codon usage was optimized for efficient gene expression in E. coli by the GeneOptimizer software. The insert was synthesized with Nterminal $6 \mathrm{x}$-His-SUMO tag and cloned into the $\mathrm{pET} 151 / \mathrm{TOPO}$ (Thermo Scientific) plasmid. Lipopolysaccharide-free E. coli BL21 (DE3) ClearColi (Lucigen) strain carrying the plasmid was grown in the LB medium supplemented with $1 \% \mathrm{NaCl}$, $1 \mathrm{mM}$ IPTG (Sigma), and ampicillin at $18{ }^{\circ} \mathrm{C}$, overnight. The use of ClearColi cells warrants that the purified overproduced protein will be free of endotoxin and lipopolysaccharide contaminants. Cells were harvested by centrifugation, resuspended in a lysis buffer $(20 \mathrm{mM}$ Tris- $\mathrm{HCl} \mathrm{pH} 8.0,500 \mathrm{mM} \mathrm{NaCl}$, $20 \mathrm{mM}$ imidazole, $10 \%$ glycerol, ROCHE protease inhibitor cocktail), and disrupted by sonication. After centrifugation, the supernatant was loaded on the HIS-Select $\AA$ Nickel Affinity Gel resin (Sigma) equilibrated with the lysis buffer. To remove unbound proteins and the chaperone-associated substrates, the column was washed with a buffer containing $5 \mathrm{mM}$ ATP, $5 \mathrm{mM}$ $\mathrm{MgCl}_{2}, 1 \mathrm{M} \mathrm{NaCl}$, and $20 \mathrm{mM}$ Tris- $\mathrm{HCl} \mathrm{pH}=8.0$. The Hsp70 containing fractions (eluted with lysis buffer containing $180 \mathrm{mM}$ imidazole) were dialyzed against a dialysis buffer (20 mM Tris-HCl pH = 8.0, $250 \mathrm{mM} \mathrm{NaCl}, 10 \%$ glycerol), followed by His-tag cleavage using SUMO protease (Sigma). To remove His-tag from the mixture, the protein sample was loaded on the HIS-Select $\AA$ Nickel Affinity Gel resin (Sigma) equilibrated with the dialysis buffer. The Hsp70 fraction (99\% purity) was filtered $(0.22 \mu \mathrm{m})$ and stored at $-80{ }^{\circ} \mathrm{C}$.

\section{PBMC culture}

Peripheral blood mononuclear cells (PBMCs) were isolated from the venous blood of healthy volunteers by Histopaque 1077 (Sigma) gradient centrifugation and cultured as described previously, with a minor modification (Tukaj et al. 2014). Briefly, PBMCs were washed with PBS and resuspended at $0.5 \times 10^{6}-$ $1 \times 10^{6}$ cells per $\mathrm{ml}$ of the medium (RPMI 1640 supplemented with $10 \%$ fetal calf serum and $1 \%$ penicillin/streptomycin; all components from Sigma). Cells were cultured in the presence of $1 \mu \mathrm{g} / \mathrm{ml}$ immobilized anti-CD3 $\varepsilon \mathrm{mAb}$ (BioLegend) and $1 \mu \mathrm{g} / \mathrm{ml}$ soluble anti-CD28 mAb (BioLegend), in 24-well culture plates, at $5 \% \mathrm{CO}_{2}$ and at $37{ }^{\circ} \mathrm{C}$ without or with different concentrations ( 1 or $10 \mu \mathrm{g} / \mathrm{ml}$ ) of the human Hsp70 for $72 \mathrm{~h}$.

\section{Detection of extracellular Hsp70}

Serum Hsp70 levels were assessed by using a commercially available HSP70 High Sensitivity (Sandwich) ELISA kit (Abcam), according to the manufacturer's instructions. The kit is designed to assay human Hsp70 in serum or plasma. Quantitative determination of HSP70 in the serum was performed based on a standard curve. The sensitivity or limit of detection of the assay is $90 \mathrm{pg} / \mathrm{ml}$.

\section{Cytokine detection}

Cell culture supernatant levels of human IL-6 were assessed by ELISA (BioLegend) prior the monensin/PMA/ionomicin addition, according to the manufacturer's instructions. Quantitative determination of IL-6 was performed based on a standard curve. 


\section{FACS immunophenotyping}

Anti-CD3/28 mAb-stimulated human PBMCs were cultured with or without the human Hsp70 protein $(1$ or $10 \mu \mathrm{g} / \mathrm{ml})$ for $72 \mathrm{~h} \mathrm{~h}$. In the case of Th1/Th2/Th17 phenotyping, monensin (BioLegend), phorbol-12-myristate-13-acetate (PMA) (50 $\mathrm{ng} / \mathrm{ml}$; Sigma), and ionomycin (1 $\mu \mathrm{g} / \mathrm{ml}$; Sigma) were added for the last $4 \mathrm{~h}$ of culture. Cells were washed, stained for the T helper cells (anti-CD4-FITC; BioLegend), fixed, permeabilized, and stained for detection of intracellular molecules using the following anti-human mAbs: anti-IFN- $\gamma$ APC, anti-IL-17-APC, anti-FoxP3-APC, and anti-IL-4-PE (BioLegend). Samples were analyzed using the CyFlow Cube 6-flow cytometer (Sysmex).

\section{Statistical analysis}

Statistical analyses were performed using the GraphPad Prism 5 (San Diego, CA) software. The Shapiro-Wilk test was used to verify whether the data had normal distribution. Nonnormal distributed data was analyzed by the Mann Whitney $U$ test, Kruskal-Wallis test, and Spearman's rank correlation test. $P$ values that were less than 0.05 were considered as statistically significant.

\section{Results}

\section{Serum levels of Hsp70 are significantly increased in the rheumatoid arthritis patients}

We found that the serum levels of Hsp70 are significantly higher $(p<0.0001)$ in the RA patients $(n=27)$ when compared to the age- and gender-matched healthy controls $(n=$ 37), as assessed by ELISA (Fig. 1). The levels of Hsp70, however, were neither associated with the disease activity $(p=0.85)$ nor the disease's progression based on the radiological Steinbrocker RTG criteria $(p=0.2)$ in the RA patients.

\section{Extracellular Hsp70 induces interleukin 6 (IL-6) secretion, stimulates Th17, and inhibits Th1 frequencies in the human PBMC cultures}

The effects of highly pure, substrate-, and endotoxin-free human Hsp70 (Fig. 2a) on secretion of IL-6 and polarization of the $\mathrm{T}$ helper cell populations [such as $\mathrm{CD} 4^{+} \mathrm{IL}-17^{+}$(Th17), $\mathrm{CD} 4^{+} \mathrm{IFN}-\gamma^{+}$(Th1), $\mathrm{CD} 4^{+} \mathrm{IL}^{-} 4^{+}$(Th2), and $\mathrm{CD} 4^{+} \mathrm{FoxP}^{+}$ (Treg)] were studied in the anti-CD3/28-stimulated naïve human peripheral blood mononuclear cell (PBMC) cultures. Hsp70 stimulated secretion of IL-6 in a dose-dependent manner (Fig. 2b). While Hsp70 induced the Th17 frequencies, the Th1 frequencies were significantly decreased in the Hsp70treated PBMC cultures. No significant effects of Hsp70 on

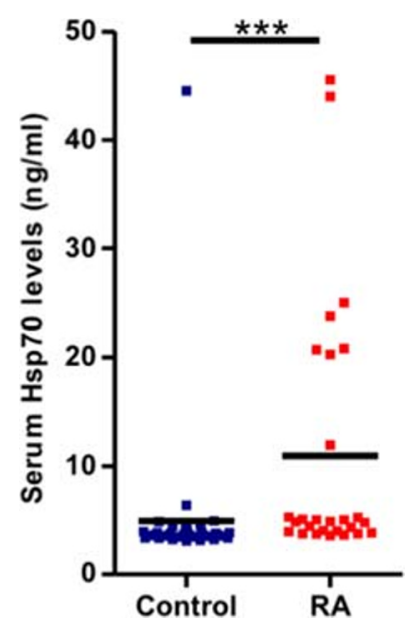

Fig. 1 Levels of Hsp70 are increased in the sera of patients with rheumatoid arthritis (RA). Serum levels of Hsp70 in RA $(n=27)$ and age- and gender-matched healthy controls $(n=37)$ were assessed by an enzyme-linked immunosorbent assay. The squares and horizontal bars indicate individual and mean values in each group, respectively. $* * * P<0.0001$

Treg and Th2 frequencies were found (Fig. 2c). In addition, Hsp70 induced the Th17/Treg ratio and decreased the Th1/ $\mathrm{Th} 2$ ratio in the PBMC cultures in a dose-dependent fashion, i.e., lower concentrations of Hsp70 $(1 \mu \mathrm{g} / \mathrm{ml})$ induced the Th17/Treg ratio, and higher concentrations of Hsp70 $(10 \mu \mathrm{g} / \mathrm{ml})$ inhibited the Th1/Th2 ratio (Fig. $2 \mathrm{~d}$ ).

\section{Discussion}

Numerous data have indicated that the heat shock proteins (Hsp) are overexpressed in inflamed tissues. Whether upregulation of Hsp in chronically inflamed tissues regulates or participates in the pathology process remains unclear. On one hand, blockade of the Hsp90 chaperone activity has led to inhibition of the (auto)immune response (Tukaj and Wegrzyn 2016). On the other hand, pharmacological induction of Hsp70 in cells has downregulated the inflammation process in preclinical models of arthritis (Wieten et al. 2007, 2010a, b; Tukaj and Wegrzyn 2016; Tukaj and Kaminski 2019). Moreover, polyphenol-mediated induction of Hsp32 (heme oxygenase-1) resulted in dramatic improvements in the prognosis of osteoarthritis symptoms in the human population (Mahmoud et al. 2015).

Preclinical observations suggest that the highly conserved bacterial/murine extracellular Hsp70 could be regarded as a potential treatment target for RA (Wendling et al. 2000; van Eden et al. 2005; Wieten et al. 2009; van Herwijnen et al. 2012; van Eden et al. 2013; Tukaj and Kaminski 2019). Physiological role of its human counterpart in the adaptive arm of the immune system, however, requires further investigation. Here, we found that the serum levels of Hsp70 are significantly higher in the RA patients when compared to healthy controls. However, the serum levels of Hsp70 did not correlate with the disease activity 
a

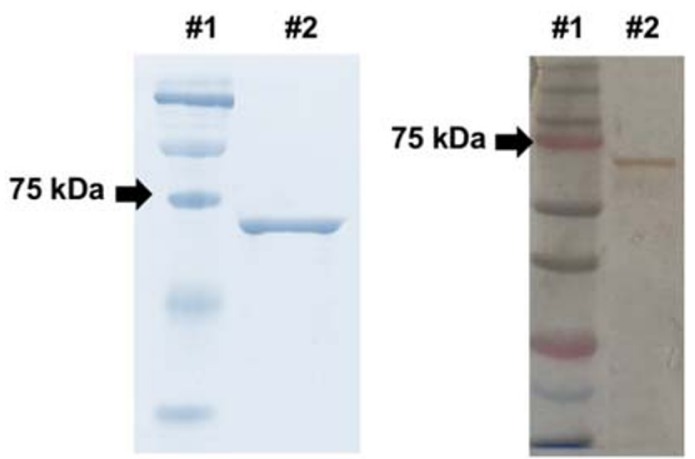

C
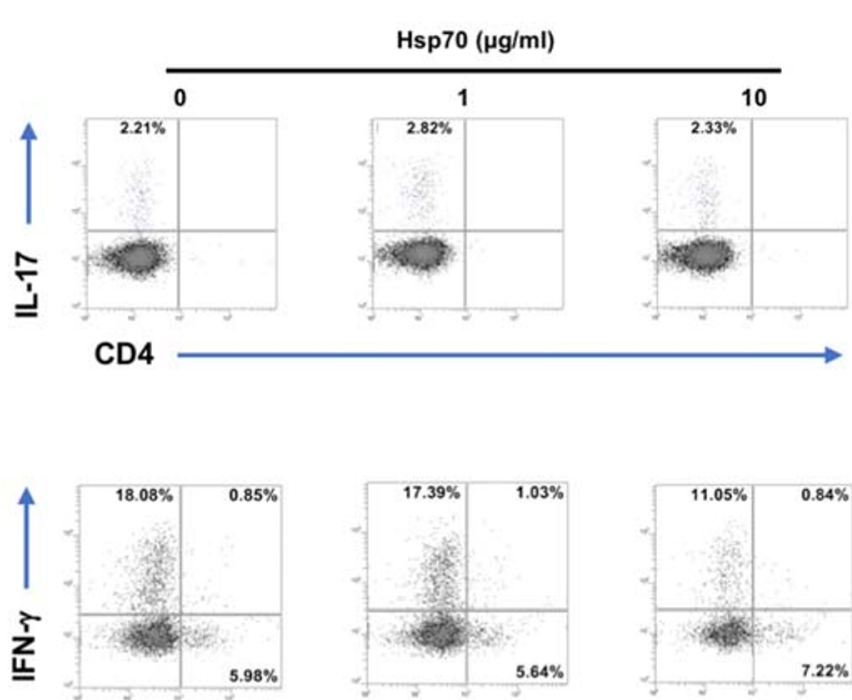

IL-4
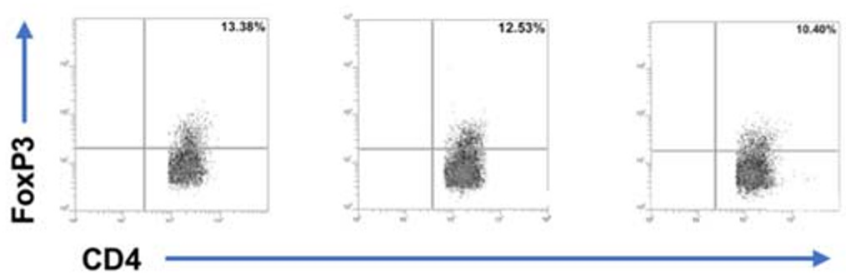

d
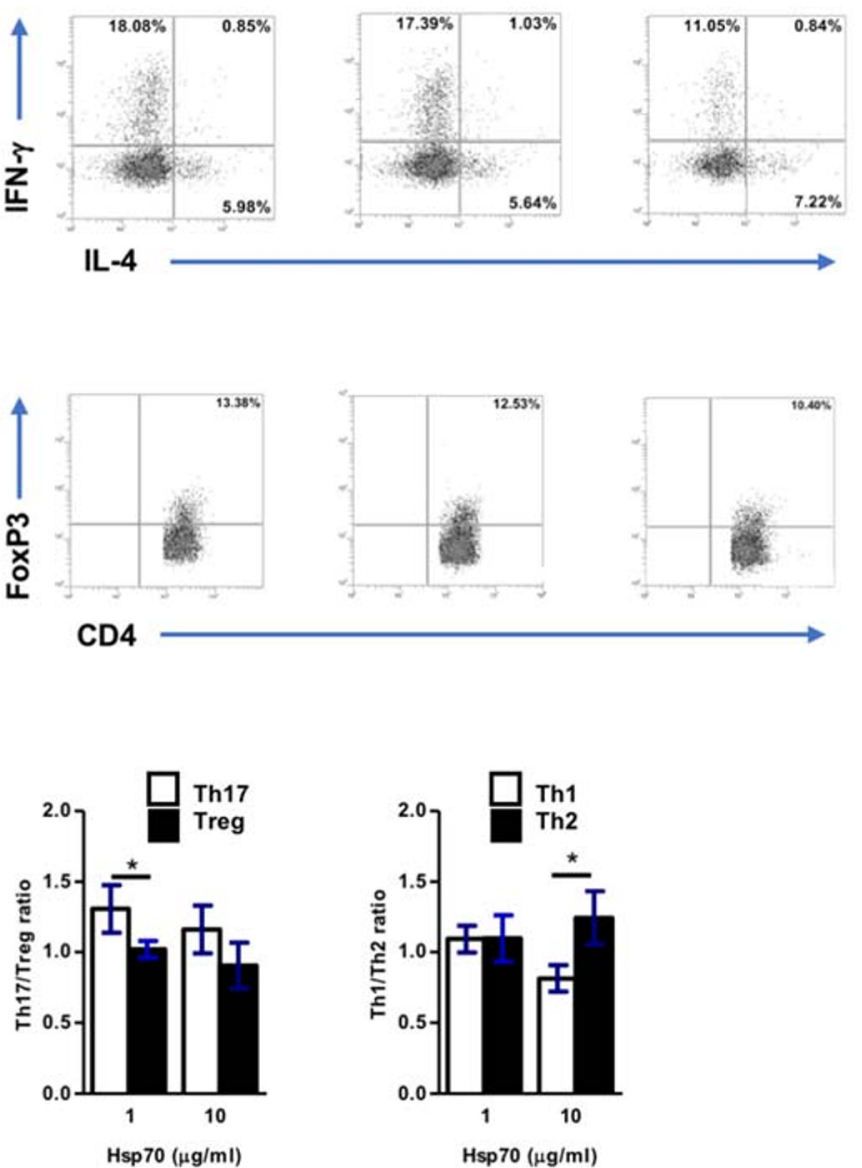

b
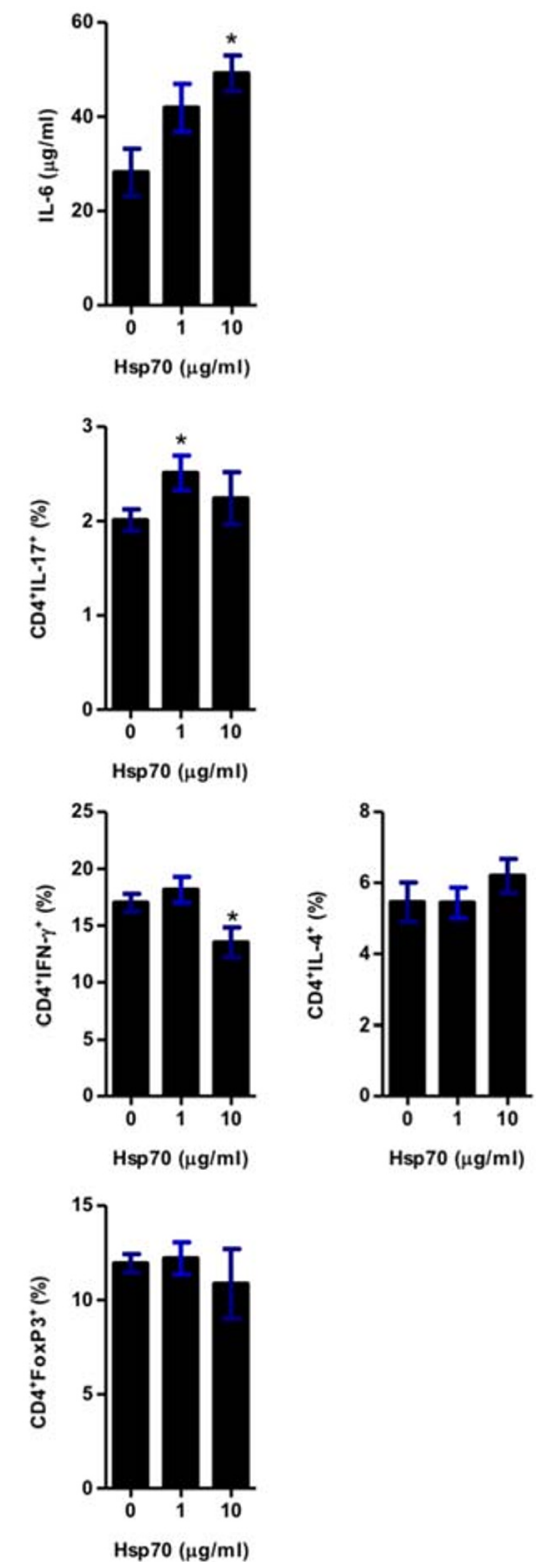

Hsp70 ( $\mu \mathrm{g} / \mathrm{ml})$

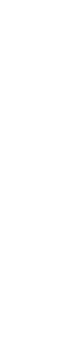


Fig. 2 Hsp70 induces IL-6 secretion, stimulates Th17, and inhibits Th1 frequencies in vitro. a Affinity-purified human Hsp70 was resolved in $10 \%$ SDS-PAGE gel and stained with Coomassie Brilliant Blue (left) and silver staining (right). Line \#1: molecular weight ladder; line \#2: Hsp70. b IL-6 levels in supernatants from human PBMC cultures stimulated with anti-CD3/CD28 mAb antibody for $68 \mathrm{~h}$ in the absence or presence of Hsp70 (1 or $10 \mu \mathrm{g} / \mathrm{ml})$. c Frequencies of Th17, Th1, Th2, and Treg cell populations in human PBMC cultures stimulated for $72 \mathrm{~h}$ with anti-CD3/ CD28 $\mathrm{mAb}$ in the absence or presence of Hsp70 (1 or $10 \mu \mathrm{g} / \mathrm{ml})$ were analyzed by flow cytometry. The numbers in the gates of the representative results are the percentages of the respective cell populations with respect to the total cell numbers. d The Th17/Treg and Th1/Th2 ratios in PBMC cultures stimulated with anti-CD3/CD28 mAb for $72 \mathrm{~h}$ in the presence of $\mathrm{Hsp} 70(1$ or $10 \mu \mathrm{g} / \mathrm{ml})$. To express the ratios, data were normalized to a mean value of the respective controls. The results are presented as mean values \pm SEM of $n=8$. The experiments were repeated twice. $* P<0.05$

ratio in the anti-CD3/28-stimulated naïve PBMC cultures. This may suggest an immunosuppressive activity of the extracellular Hsp70 because RA is considered as an autoimmune disease driven by the pro-inflammatory Th1 cells. These cells predominate over the Th2 subset that exerts regulatory functions (Schulze-Koops and Kalden 2001). On the other hand, Hsp70 induced the Th17 frequencies and the Th17/Treg ratio in the investigated PBMC cultures, pointing towards its proinflammatory activity. The pro-inflammatory activity of extracellular Hsp70 may explain the presence of a positive correlation between the serum levels of Hsp70 and the disease progression and activity in RA (Najafizadeh et al. 2015). However, these observations are not consistent with previous pre-clinical reports that had shown that artificial immunization with highly conserved bacterial and/or murine Hsp70 peptides could be regarded as a potential treatment target for RA via induction of the antigen-specific Treg cells (van Herwijnen et al. 2012; Tukaj and Kaminski 2019). Lack of stimulatory effects of Hsp70 on the expansion of Treg in our study can be simply explained by the differences between culture conditions and the animal models. Moreover, induction of the antigen (Hsp70)specific Treg in animal models of arthritis strictly depends on the immunological niche or the use of bacterial/murine-derived peptides. This discrepancy can be also explained by changes in the autoimmune response to Hsp70 caused by the active immunization procedure, ranging from a pro-inflammatory phenotype to a more tolerogenic functional phenotype, as it has been already described in the context of RA therapy by using an Hsp40-derived dnaJP1 peptide (Koffeman et al. 2009). Mucosal induction of the immune tolerance to dnaJP1 has led to a qualitative change from a pro-inflammatory phenotype to a tolerogenic one and to a clinical efficacy in RA patients (Koffeman et al. 2009). Moreover, the immunosuppressive activity of the extracellular autologous Hsp70 needs to be further investigated, especially in the context of its stimulatory effects on the interleukin 6 (IL-6) secretion in vitro. IL-6 is significantly increased in the sera of RA patients and is positively correlated with the disease's activity and progression (Tukaj et al.
2010). On one hand, IL-6 produced by professional antigen presenting cells in response to different antigen stimuli can modulate the Th1/Th2 balance towards Th2 (Dienz and Rincon 2009). On the other hand, IL-6 promotes differentiation of pro-arthritis Th17 cells, blocks generation of the Treg cells, and triggers systemic inflammatory processes in RA (Schinnerling et al. 2017). Therefore, we hypothesize that the dual role of Hsp70 on Th1/Th2 and Th17/Treg T helper cell polarization is IL-6-dependent. In addition, stimulatory effects of Hsp70 on IL-6 secretion, a potent activator of the humoral (auto)immune response, might explain the presence of autoantibodies to self-Hsp70; these autoantibodies are known to be elevated in RA patients (Mantej et al. 2019). In fact, autoantibodies to Hsp70 may regulate the immune response, as evidenced by the presence of a negative correlation between the serum levels of anti-Hsp70 autoantibodies and the proinflammatory TNF- $\alpha$ in RA patients (Mantej et al. 2019). This phenomenon is also partly consistent with previous observations in regard to the other class of molecular chaperones, such as Hsp60. Naturally occurring or acquired antibodies to M. tuberculosis Hsp60, as well as humanized anti-Hsp60 mAb, protected against arthritis induction in an experimental model (Ulmansky et al. 2002, 2015). In addition, humanized antiHsp60 mAb induced secretion of the anti-inflammatory IL-10 and suppressed secretion of IFN- $\gamma$ and IL- 6 in the human naïve PBMC cultures (Ulmansky et al. 2015).

Taken together, this study aimed to identify the key pieces of evidence on human Hsp70 involvement in T helper cell polarization based on in vitro observations using PBMCs from healthy individuals. Although the obtained results are promising, they are nevertheless preliminary and require further investigation to validate the model we propose.

Acknowledgments We are grateful to Prof. Ewa Bryl and Prof. Jacek M. Witkowski from the Medical University of Gdańsk for providing us sera samples from RA patients.

Funding information This study was supported by the Polish National Science Centre (NCN), grant no. 2017/25/B/NZ6/00305.

Compliance with ethical standards The use of human biological material was approved by the Ethics Committee of the Medical University of Gdańsk, Poland, and written informed consent was obtained according to the Declaration of Helsinki.

Conflict of interest The authors declare that they have no conflict of interest.

Open Access This article is licensed under a Creative Commons Attribution 4.0 International License, which permits use, sharing, adaptation, distribution and reproduction in any medium or format, as long as you give appropriate credit to the original author(s) and the source, provide a link to the Creative Commons licence, and indicate if changes were made. The images or other third party material in this article are included in the article's Creative Commons licence, unless indicated otherwise in a credit line to the material. If material is not included in the article's Creative Commons licence and your intended use is not permitted by 
statutory regulation or exceeds the permitted use, you will need to obtain permission directly from the copyright holder. To view a copy of this licence, visit http://creativecommons.org/licenses/by/4.0/.

\section{References}

Angelotti F, Parma A, Cafaro G, Capecchi R, Alunno A, Puxeddu I (2017) One year in review 2017: pathogenesis of rheumatoid arthritis. Clin Exp Rheumatol 35:368-378

Borges TJ, Wieten L, van Herwijnen MJ, Broere F, van der Zee R, Bonorino C, van Eden W (2012) The anti-inflammatory mechanisms of Hsp70. Front Immunol 3:95. https://doi.org/10.3389/ fimmu.2012.0009

Dienz O, Rincon M (2009) The effects of IL-6 on CD4 T cell responses. Clin Immunol 130:27-33. https://doi.org/10.1016/j.clim.2008.08.018

Firestein GS, McInnes IB (2017) Immunopathogenesis of rheumatoid arthritis. Immunity 46:183-196. https://doi.org/10.1016/j.immuni. 2017.02.006

Koffeman EC, Genovese M, Amox D, Keogh E, Santana E, Matteson EL, Kavanaugh A, Molitor JA, Schiff MH, Posever JO, Bathon JM, Kivitz AJ, Samodal R, Belardi F, Dennehey C, van den Broek T, van Wijk F, Zhang X, Zieseniss P, le T, Prakken BA, Cutter GC, Albani S (2009) Epitope-specific immunotherapy of rheumatoid arthritis: clinical responsiveness occurs with immune deviation and relies on the expression of a cluster of molecules associated with $\mathrm{T}$ cell tolerance in a double-blind, placebo-controlled, pilot phase II trial. Arthritis Rheum 60:3207-3216. https://doi.org/10.1002/art.24916

Mahmoud FF, Al-Awadhi AM, Haines DD (2015) Amelioration of human osteoarthritis symptoms with topical 'biotherapeutics': a phase I human trial. Cell Stress Chaperones 20:267-276. https://doi.org/10. 1007/s12192-014-0553-0

Mantej J, Polasik K, Piotrowska E, Tukaj S (2019) Autoantibodies to heat shock proteins 60,70 , and 90 in patients with rheumatoid arthritis. Cell Stress Chaperones 24:283-287. https://doi.org/10.1007/ s12192-018-0951-9

McInnes IB, Schett G (2011) The pathogenesis of rheumatoid arthritis. N Engl J Med 365:2205-2219. https://doi.org/10.1056/NEJMra1004965

Najafizadeh SR, Ghazizadeh Z, Nargesi AA, Mahdavi M, Abtahi S, Mirmiranpour H, Nakhjavani M (2015) Analysis of serum heat shock protein 70 (HSPA1A) concentrations for diagnosis and disease activity monitoring in patients with rheumatoid arthritis. Cell Stress Chaperones 20:537-543. https://doi.org/10.1007/s12192015-0578-Z

Pockley AG, Henderson B (2018) Extracellular cell stress (heat shock) proteins-immune responses and disease: an overview. Philos Trans R Soc Lond B Biol Sci 373(1738). https://doi.org/10.1098/rstb.2016.0522

Radons J (2016) The human HSP70 family of chaperones: where do we stand? Cell Stress Chaperones 21:379-404. https://doi.org/10.1007/ s12192-016-0676-6

Schinnerling K, Aguillón JC, Catalán D, Soto L (2017) The role of interleukin-6 signalling and its therapeutic blockage in skewing the T cell balance in rheumatoid arthritis. Clin Exp Immunol 189:12-20. https://doi.org/10.1111/cei.12966

Schulze-Koops H, Kalden JR (2001) The balance of Th1/Th2 cytokines in rheumatoid arthritis. Best Pract Res Clin Rheumatol 15:677-691

Tukaj S, Kaminski M (2019) Heat shock proteins in the therapy of autoimmune diseases: too simple to be true? Cell Stress Chaperones 24: 475-479. https://doi.org/10.1007/s12192-019-01000-3

Tukaj S, Wegrzyn G (2016) Anti-Hsp90 therapy in autoimmune and inflammatory diseases: a review of preclinical studies. Cell Stress Chaperones 21:213-218. https://doi.org/10.1007/s12192-016-0670-Z
Tukaj S, Kotlarz A, Jóźwik A, Smoleńska Z, Bryl E, Witkowski JM, Lipińska B (2010) Cytokines of the Th1 and Th2 type in sera of rheumatoid arthritis patients; correlations with anti-Hsp40 immune response and diagnostic markers. Acta Biochim Pol 57:327-332

Tukaj S, Zillikens D, Kasperkiewicz M (2014) Inhibitory effects of heat shock protein 90 blockade on proinflammatory human Th1 and Th17 cell subpopulations. J Inflamm (Lond) 11:10. https://doi.org/ 10.1186/1476-9255-11-10

Ulmansky R, Cohen CJ, Szafer F, Moallem E, Fridlender ZG, Kashi Y, Naparstek Y (2002) Resistance to adjuvant arthritis is due to protective antibodies against heat shock protein surface epitopes and the induction of IL-10 secretion. J Immunol 168:6463-6469

Ulmansky R, Landstein D, Moallem E, Loeb V, Levin A, Meyuhas R, Katzavian G, Yair S, Naparstek Y (2015) A humanized monoclonal antibody against heat shock protein 60 suppresses murine arthritis and colitis and skews the cytokine balance toward an antiinflammatory response. J Immunol 194:5103-5109. https://doi. org/10.4049/jimmunol.1500023

van Eden W (2018) Immune tolerance therapies for autoimmune diseases based on heat shock protein T-cell epitopes. Philos Trans R Soc Lond B Biol Sci 373(1738). https://doi.org/10.1098/rstb.2016.0531

van Eden W, van der Zee R, Prakken B (2005) Heat-shock proteins induce Tcell regulation of chronic inflammation. Nat Rev Immunol 5:318-330

van Eden W, van Herwijnen M, Wagenaar J, van Kooten P, Broere F, van der Zee R (2013) Stress proteins are used by the immune system for cognate interactions with anti-inflammatory regulatory $\mathrm{T}$ cells. FEBS Lett 587 : 1951-1958. https://doi.org/10.1016/j.febslet.2013.05.024

van Herwijnen MJ, Wieten L, van der Zee R, van Kooten PJ, WagenaarHilbers JP, Hoek A, den Braber I, Anderton SM, Singh M, Meiring HD, van Els CA, van Eden W, Broere F (2012) Regulatory T cells that recognize a ubiquitous stress-inducible self-antigen are longlived suppressors of autoimmune arthritis. Proc Natl Acad Sci U S A 109:14134-14139. https://doi.org/10.1073/pnas.1206803109

Wendling U, Paul L, van der Zee R, Prakken B, Singh M, van Eden W (2000) A conserved mycobacterial heat shock protein (hsp) 70 sequence prevents adjuvant arthritis upon nasal administration and induces IL-10-producing T cells that cross-react with the mammalian self-hsp70 homologue. J Immunol 164:2711-2717

Wieten L, Broere F, van der Zee R, Koerkamp EK, Wagenaar J, van Eden W (2007) Cell stress induced HSP are targets of regulatory T cells: a role for HSP inducing compounds as anti-inflammatory immunomodulators? FEBS Lett 581:3716-3722. https://doi.org/10.1016/j. febslet.2007.04.082

Wieten L, Berlo SE, Ten Brink CB, van Kooten PJ, Singh M, van der Zee R, Glant TT, Broere F, van Eden W (2009) IL-10 is critically involved in mycobacterial HSP70 induced suppression of proteoglycan-induced arthritis. PLoS One 4:e4186. https://doi.org/ 10.1371/journal.pone. 0004186

Wieten L, van der Zee R, Goedemans R, Sijtsma J, Serafini M, Lubsen NH, van Eden W, Broere F (2010a) Hsp70 expression and induction as a readout for detection of immune modulatory components in food. Cell Stress Chaperones 15:25-37. https://doi.org/10.1007/s12192-009-0119-8

Wieten L, van der Zee R, Spiering R, Wagenaar-Hilbers J, van Kooten P, Broere F, van Eden W (2010b) A novel heat-shock protein coinducer boosts stress protein $\mathrm{Hsp} 70$ to activate $\mathrm{T}$ cell regulation of inflammation in autoimmune arthritis. Arthritis Rheum 62:1026 1035. https://doi.org/10.1002/art.27344

Zlacka D, Vavrincova P, Hien Nguyen TT, Hromadnikova I (2006) Frequency of anti-hsp60, -65 and -70 antibodies in sera of patients with juvenile idiopathic arthritis. J Autoimmun 27:81-88

Publisher's note Springer Nature remains neutral with regard to jurisdictional claims in published maps and institutional affiliations. 